\title{
CONTEXTUAL RELATIONSHIP AMONG THE QUALITY ENABLED FACTORS OF INVENTORY CONTROL SYSTEM STAGE
}

\author{
Rajesh Attri ${ }^{1}$ and Sandeep Grover ${ }^{1}$ \\ ${ }^{1}$ Department of Mechanical Engineering, YMCA University of Science \& Technology, \\ Faridabad, Haryana, India
}

\begin{abstract}
The main purpose of this paper is to comprehend the contextual relation among the different quality enabled factors (QEFs) of inventory control system stage of production system life cycle. Interpretative structural modelling (ISM) approach is utilized to cultivate the relationship among the identified QEFs of inventory control system stage. Afterwards, MICMAC (cross-impact matrix multiplication applied to classification) analysis has been applied in order to identify and classify the imperative QEFs and disclose the direct and indirect effects of each QEF on the inventory control system stage of production system life cycle.
\end{abstract}

\section{KEYWORDS}

Inventory control, quality enabled factors, ISM, QEF, MICMAC

\section{INTRODUCTION}

Inventory control system stage is an important phase of the production system life cycle (PSLC). Inventory control system provides the operational policies to the organizations for upholding and monitoring the goods or items to be inventoried. These operating policies assist in the smooth functioning of the operation of an organization. The main aim of the inventory control system is to ensure the availability of materials in appropriate quantity as and when required along with the minimization of investment in inventories [1].

Inventory basically refers to the stock of the goods or item to be well-maintained for the smooth working of the organization. So, inventory management is considered as a backbone for all the organizations for the growth, survival or success of a business. Moreover, poor inventory management can lead to reduced sales which in turn can result in the failure of a business [2]. Inventory signifies a major financial asset for any organization as it represents the 25 to 50 per cent of total assets [3]. The organization must aim at adequate inventory level for all necessary items along with minimum inventory cost.

In literature, a number of mathematical models (like Basic EOQ model; Dynamic economic lot size model; periodic review stochastic demand model) are available for assisting the decision makers in making the appropriate decisions regarding the placement of replenishment order along with the order quantity. These inventory control models are based on certain assumptions about the demand, cost structure and system nature. Moreover, several authors have tried to suggest the approximation algorithms for the inventory control models. The goal of these 
approximation algorithms is to coordinate the sequence of demand orders along with the minimum ordering, holding and backlogging costs.

The inventory control system stage of production system life cycle is affected by a number of factors (hereby known as quality enabled factors) which affect the quality of decisions made in this stage. These factors not only affect the decisions in inventory control stage but also affect one another. So it is very essential to recognize the nature of these factors so that the driving factors (which supports the other factor) and dependent factors (which are influenced by the other factors) are recognized. For this purpose, Interpretive Structural Modelling (ISM) approach has been utilized.

The main objectives of the current work are as follows:

- To identify the quality enabled factors (QEFs) affecting the inventory control system stage of PSLC;

- To validate the QEFs using the questionnaire based survey;

- To institute relationships among these identified QEFs using the ISM approach; and

- To classify the QEFs into different categories.

- To evaluate and examine the driving power and dependence power of the QEFs to help the decision makers in making correct decisions.

\section{IDENTIFICATION OF QUALITY ENABLED FACTORS (QEFS) AFFECTING INVENTORY CONTROL SYSTEM STAGE}

The various quality enabled factors (QEFs) affecting the inventory control system stage are identified from the extensive literature analysis and opinions of experts (academic and industrial) as epitomized in Figure 1. The details of QEFs are described underneath.

Accurate level of safety stock: Safety stock is also known as buffer stock. It defines a level of additional stock that is preserved to alleviate risk of deficit in material due to uncertainties in supply and demand. Adequate safety stock levels permit business operations to continue according to their strategies [4].

Accurate inventory cost analysis: The production and store department of organization should carry out accurate cost analysis (inventory carrying cost, set-up cost, and shortage cost) while deciding the level of inventory to be maintained. Inventory carrying costs arethe cost incurred for requiring items physically in the store. Set-up costs are costs of ordering and receiving inventory. Shortage costs outcomes when demand exceeds the supply of inventory.

Accurate size of economic purchase order: Economic order quantity is that order quantity at which total inventory holding costs and ordering costs are minimum. The economic order size of the purchase order depends upon the inventory policy being utilized by the organization.

Accurate timing of order placement: The accurate timings of order placement also play an important role in inventory management. It also affects the inventory carrying cost of an organization. 
Application of computer based software's for inventory management: Now days, a number of computer based program are utilized for inventory management and control. The computer based program to be utilized depends upon the nature of demand i.e. dependent demand and independent demand. For the dependent demand, IMPACT (Inventory Management Program and Control Techniques Software System) developed by IBM is most widely utilized. For dependent demand, computerized Material Requirements Planning (MRP) system, PICS (Production and Information Control system), COPICS (Communications Oriented Production Information and Control System) are used.

Accurate inventory control policy: Inventory can be controlled by two practices or techniques such as: (a) Qualitative techniques, (b) Quantitative techniques. Qualitative techniques include ABC classification, FSN classification and VED classification, while Quantitative techniques include deterministic models, and probabilistic or non-deterministic models. In deterministic type, demand of an item is known and fixed, however in probabilistic type, the demand of an item is not known.

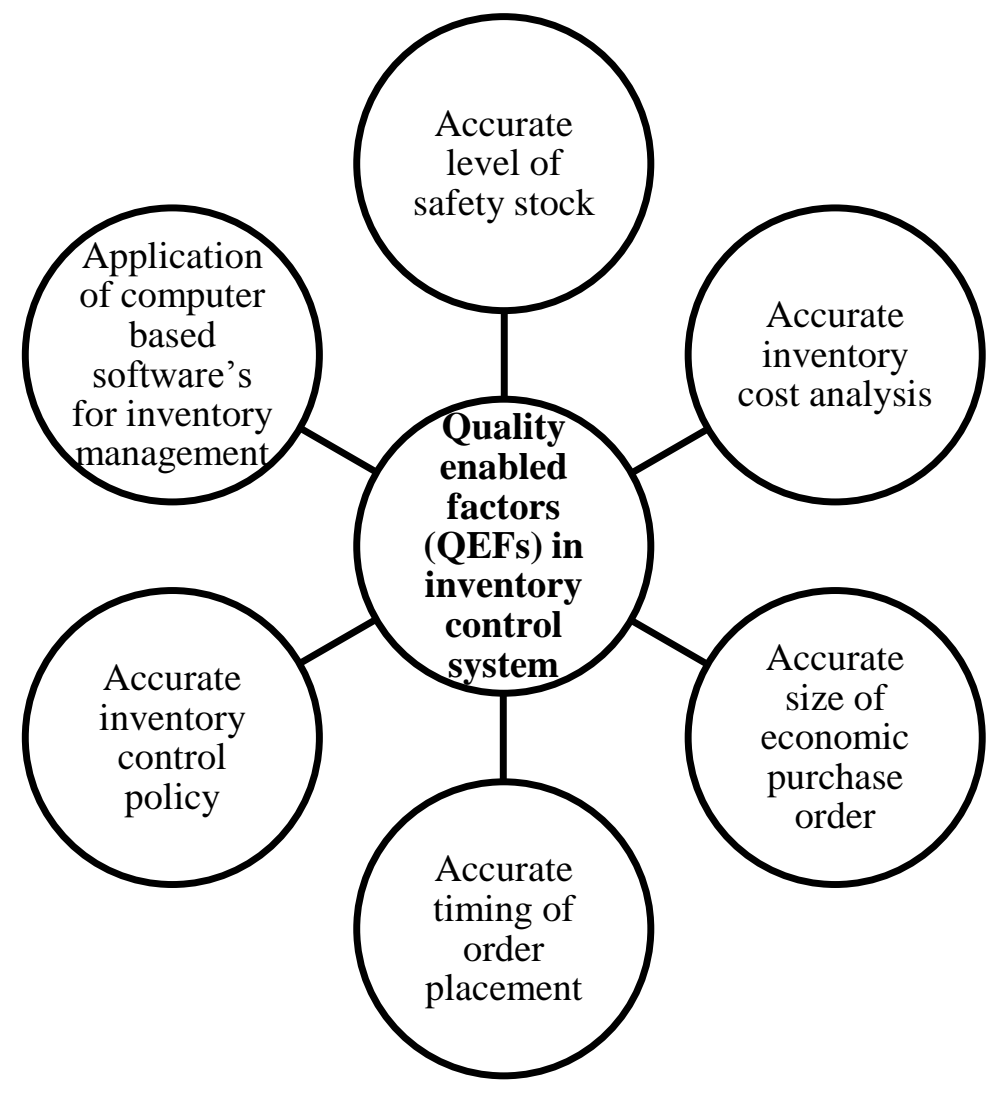

Figure 1.Quality enabled factors of inventory control system stage

After the identification of QEFs of inventory control system stage of PSLC, the QEFs are validated by using the questionnaire based survey. For this purpose, a questionnaire was prepared on the Likart scale (1-5 scale). On this scale, 1 represents least significant and 5 represents most significant individually. The questionnaires were mailed to 170 manufacturing organizations of India. The response rate of survey was $38.23 \%$.

The survey data for the QEFs of inventory control system stage as anlayzed by SPSS software is presented in Table 1. 
Table 1.Survey data of QEFs of inventory control system stage

\begin{tabular}{lccccc}
\hline \multicolumn{1}{c}{ QEFs } & Mean & Median & Mode & $\begin{array}{l}\text { Standard } \\
\text { Deviation }\end{array}$ & Range \\
\hline Accurate level of safety stock & 3.88 & 4 & 4 & 0.718 & 3 \\
Accurate inventory cost analysis & 3.86 & 4 & 4 & 0.704 & 2 \\
$\begin{array}{l}\text { Accurate size of economic } \\
\text { purchase order } 3.89\end{array}$ & 4 & 4 & 0.753 & 3 \\
$\begin{array}{l}\text { Accurate timing of order } \\
\text { placement } 3.91\end{array}$ & 4 & 4 & 0.701 & 2 \\
$\begin{array}{l}\text { Application of computer based } \\
\text { software's for inventory } \\
\text { management }\end{array}$ & 3.58 & 4 & 4 & 0.727 & 3 \\
Accurate inventory control policy & 3.78 & 4 & 4 & 0.696 & 3 \\
\hline
\end{tabular}

Table 1 reveals that identified QEFs of inventory control system stage are having good impact in the manufacturing organizations. Moreover, Kendall Tau-b correlation (two-tailed) test among the identified QEFs was carried out (Table 2) for checking the occurrence of multicollinearity. Table 2 reveals that all the identified QEFs are highly correlated to each other.

Table 2. Correlation coefficients for inventory control system stage QEFs

\begin{tabular}{|c|c|c|c|c|c|c|c|}
\hline QEFs & & $\mathbf{F}_{1}$ & $\mathbf{F}_{2}$ & $\mathbf{F}_{3}$ & $\mathbf{F}_{4}$ & $\mathbf{F}_{5}$ & $\mathbf{F}_{6}$ \\
\hline Accurate level of safety stock & $\mathbf{F}_{1}$ & & $0.424^{* * *}$ & $0.356^{* *}$ & 0.180 & -0.099 & -0.027 \\
\hline Accurate inventory cost analysis & $\mathbf{F}_{2}$ & & & $0.377^{* *}$ & 0.155 & 0.014 & 0.143 \\
\hline $\begin{array}{l}\text { Accurate size of economic } \\
\text { purchase order }\end{array}$ & $\mathbf{F}_{3}$ & & & & 0.084 & 0.085 & 0.215 \\
\hline $\begin{array}{l}\text { Accurate timing of order } \\
\text { placement }\end{array}$ & $\mathbf{F}_{4}$ & & & & & $0.230^{*}$ & 0.035 \\
\hline $\begin{array}{l}\text { Application of computer based } \\
\text { software's for inventory } \\
\text { management }\end{array}$ & $\mathbf{F}_{5}$ & & & & & & 0.213 \\
\hline Accurate inventory control policy & $\mathbf{F}_{6}$ & & & & & & \\
\hline
\end{tabular}

\section{INTERPRETIVE STRUCTURAL MODELLING APPROACH}

Interpretive structural modelling (ISM) is an extensively used structural modelling approach for developing the hierarchical relationships within a set of elements on the basis of information achieved through group exercise [5-6]. The first demonstration of the ISM approach was done by Malone [7] for analysing the barriers in investment in an urban city. ISM approach transforms the unclear, poorly articulated mental models of systems into visible, well-defined models which can be used for many functions [8-10]. This approach can be effectively utilized by the individuals as well as by the group. It is a suitable method for analysing the influence of one factor over the another factor [11]. 
The various steps involved in ISM approach are as follows [12-17]:

- Identification of QEFs related to an issue or problem. This is generally done by literature analysis, expert opinions or by using any group problem solving method.

- Establishment of the contextual relationship among the identified QEFs(done in previous step) with respect to which pairs of QEFswill be analyzed.

- Development of a structural self-interaction matrix (SSIM) of identified QEFs. SSIM shows the pair-wise relationship among the QEFsof an issue or problem under consideration

- Development of initial reachability matrix (IRM) from SSIM (developed in earlier step), and final reachability matrix (FRM) by the introduction of transitivity concept in the IRM. Transitivity is considered as the basic assumption in ISM approach. It specifies that if QEF-A is related to QEF-B and QEF-B is related to QEF-C, then QEFA will be related to QEF-C.

- Partitioning of final reachability matrix (FRM) into different levels.

- Development of conical matrix from the FRM.

- Development of directed graph (digraph) on the basis of relationships found in FRM after eliminating the transitive links

- Conversion of the digraph (developed in previous step) into an ISM model, by substituting element (QEF) nodes with statements.

- Evaluation of the ISM model (developed in previous step) to check the conceptual inconsistency, and carry out the necessary modifications as per requirement.

ISM approach has been utilized by a number of researcher's for dealing different types of problems in different area of engineering and management. Pandi et al. [18] have evaluated the importance of critical success factors (CSFs) in the successful implementation of the IEQMS model in EEIs through the ISM approach. Faisal [19] has analyzed the barriers to corporate social responsibility in supply chains using an interpretive structural modelling approach. Singh and Kant [20] have analyzed the barriers of knowledge management using the ISM approach. Mehta et al. [21] have developed an ISM based model for the implementation of total quality management in engineering education in India. Govindan et al. [22] have analyzed green supply chain management practices in Brazil's electrical/electronic industries using ISM approach.

\section{ISM MODEL DEVELOPMENT}

The various steps of ISM approach when applied to the identified QEFs of inventory control system stage of PSLC leads to the development of an ISM model, as illustrated below:

\subsection{Structural self-interaction matrix (SSIM)}

In this step of ISM approach, SSIM is developed after taking the opinions from experts. These experts were from the industrial and academic background. In the current work, three experts from the industry and two from the academic were consulted for determining the nature of 
relationship along with the associated direction between the QEFs ( $i$ and j). For analysing the QEF, a contextual relationship of "leads to" is adopted. This means that one QEF influences another QEF. On the basis of this relationship, contextual relationship among the QEF is identified. For stating the relationship among the identified QEFs of inventory control system, following four symbols have been used for denoting the direction of relationship between the QEFs (i and j):

- $\quad \mathrm{V}$ : QEF i influences QEF j;

- A: QEF j influences QEF i;

- X: QEFs i and $\mathrm{j}$ influences each other; and

- O: QEFs i and $\mathrm{j}$ are unrelated.

On the basis of identified contextual relationships, SSIM is developed as shown in Table 3.

Table 3.Structural self-interactive matrix (SSIM)

\begin{tabular}{|c|c|c|c|c|c|c|c|}
\hline QEFs & & $\mathbf{F}_{6}$ & $\mathbf{F}_{5}$ & $\mathbf{F}_{4}$ & $\mathbf{F}_{3}$ & $\mathbf{F}_{2}$ & $\mathbf{F}_{1}$ \\
\hline Accurate level of safety stock & $\mathbf{F}_{1}$ & $\mathrm{X}$ & $\mathrm{O}$ & V & V & $\mathrm{V}$ & \\
\hline Accurate inventory cost analysis & $\mathbf{F}_{2}$ & V & $\mathrm{O}$ & V & A & & \\
\hline $\begin{array}{l}\text { Accurate size of economic purchase } \\
\text { order }\end{array}$ & $\mathbf{F}_{\mathbf{3}}$ & V & $\mathrm{O}$ & V & & & \\
\hline Accurate timing of order placement & $\mathbf{F}_{4}$ & A & A & & & & \\
\hline $\begin{array}{l}\text { Application of computer based } \\
\text { software's for inventory } \\
\text { management }\end{array}$ & $\mathbf{F}_{5}$ & $\mathrm{~V}$ & & & & & \\
\hline Accurate inventory control policy & $\mathbf{F}_{6}$ & & & & & & \\
\hline
\end{tabular}

\subsection{Development of initial and final reachability matrix}

Initial reachability matrix (IRM) is developed by transforming the SSIM into a binary matrix by replacing V, A, X, O symbols by binary digits ( 1 and 0$)$ as per the case. The replacement of SSIM symbols (V, A, $\mathrm{X}$ and $\mathrm{O})$ is carried out by using the following rules:

- If ( $i, j$ ) entry in SSIM is $V$, then $(i, j)$ entry in IRM becomes 1 and the $(j, i)$ entry becomes 0 .

- If (i, j) entry in SSIM is A, then ( $i, j)$ entry in IRM becomes 0 and the (j, i) entry becomes 1 .

- If (i, j) entry in SSIM is X, then (i, j) and ( $j, i)$ entry in IRM becomes 1

- If $(i, j)$ entry in SSIM is $O$, then $(i, j)$ and $(j, i)$ entry in IRM becomes 0 .

On following the above-mentioned rules, IRM is developed (Table 4)

Table 4.Initial reachability matrix (IRM)

\begin{tabular}{ccccccc}
\hline $\mathbf{Q E F}$ & $\mathbf{F}_{\mathbf{1}}$ & $\mathbf{F}_{\mathbf{2}}$ & $\mathbf{F}_{\mathbf{3}}$ & $\mathbf{F}_{\mathbf{4}}$ & $\mathbf{F}_{\mathbf{5}}$ & $\mathbf{F}_{\mathbf{6}}$ \\
\hline $\mathbf{F}_{\mathbf{1}}$ & 1 & 1 & 1 & 1 & 0 & 1 \\
$\mathbf{F}_{\mathbf{2}}$ & 0 & 1 & 0 & 1 & 0 & 1 \\
$\mathbf{F}_{\mathbf{3}}$ & 0 & 1 & 1 & 1 & 0 & 1 \\
$\mathbf{F}_{\mathbf{4}}$ & 0 & 0 & 0 & 1 & 0 & 0 \\
$\mathbf{F}_{\mathbf{5}}$ & 0 & 0 & 0 & 1 & 1 & 1 \\
$\mathbf{F}_{\mathbf{6}}$ & 1 & 0 & 0 & 1 & 0 & 1 \\
\hline
\end{tabular}


Final reachability matrix (FRM) is developed by the introduction of transitivity concept in the IRM (Table 4) as shown in Table 5.

Table 5.Final reachability matrix (FRM)

\begin{tabular}{ccccccc}
\hline $\mathbf{Q E F}$ & $\mathbf{F}_{\mathbf{1}}$ & $\mathbf{F}_{\mathbf{2}}$ & $\mathbf{F}_{\mathbf{3}}$ & $\mathbf{F}_{\mathbf{4}}$ & $\mathbf{F}_{\mathbf{5}}$ & $\mathbf{F}_{\mathbf{6}}$ \\
\hline $\mathbf{F}_{\mathbf{1}}$ & 1 & 1 & 1 & 1 & 0 & 1 \\
$\mathbf{F}_{\mathbf{2}}$ & $1^{*}$ & 1 & 0 & 1 & 0 & 1 \\
$\mathbf{F}_{\mathbf{3}}$ & $1^{*}$ & 1 & 1 & 1 & 0 & 1 \\
$\mathbf{F}_{\mathbf{4}}$ & 0 & 0 & 0 & 1 & 0 & 0 \\
$\mathbf{F}_{\mathbf{5}}$ & $1^{*}$ & 0 & 0 & 1 & 1 & 1 \\
$\mathbf{F}_{\mathbf{6}}$ & 1 & $1^{*}$ & $1^{*}$ & 1 & 0 & 1 \\
\hline
\end{tabular}

Note: $1 *$ entries are included to incorporate transitivity

\subsection{Level partitioning}

Partitioning of level is carried out by founding the reachability, antecedent set and intersection set for each QEF from the FRM. Reachability set consists of the QEF itself along with the other QEFs that it may influence while antecedent set consists of the QEF itself along with the other QEFs which may influence it. After the identification of these sets, intersection set is found for each QEF. The QEFs for which the reachability set and intersection set are same, occupies the top level in the ISM model. These top-level QEFs will not help to achieve the other QEFs above their own level. After the identification of the top level QEFs, it is separated from the other QEFs. Then, same procedure is repeated to find the next level QEFs and this process is continued till the level of each QEF is found. These identified levels of QEFs help in building the digraph and ISM model. The levels of QEFs are found in four iterations as presented in Tables 6-9.

Table 6.Iteration 1

\begin{tabular}{|c|c|c|c|c|}
\hline $\begin{array}{c}\text { QEFs } \\
\left(\mathbf{F}_{\mathbf{i}}\right)\end{array}$ & $\begin{array}{l}\text { Reachability set } \\
\mathbf{R}\left(\mathbf{F}_{\mathbf{i}}\right)\end{array}$ & $\begin{array}{l}\text { Antecedent set } \\
\text { A }\left(\mathbf{F}_{\mathbf{i}}\right)\end{array}$ & $\begin{array}{l}\text { Intersection set } \\
\mathbf{R}\left(\mathbf{F}_{\mathbf{i}}\right) \cap \mathbf{A}\left(\mathbf{F}_{\mathbf{i}}\right)\end{array}$ & Level \\
\hline $\mathbf{F}_{1}$ & $\mathrm{~F}_{1}, \mathrm{~F}_{2}, \mathrm{~F}_{3}, \mathrm{~F}_{4}, \mathrm{~F}_{6}$ & $\mathrm{~F}_{1}, \mathrm{~F}_{2}, \mathrm{~F}_{3}, \mathrm{~F}_{5}, \mathrm{~F}_{6}$ & $\mathrm{~F}_{1}, \mathrm{~F}_{2}, \mathrm{~F}_{3}, \mathrm{~F}_{6}$ & \\
\hline $\mathbf{F}_{2}$ & $\mathrm{~F}_{1}, \mathrm{~F}_{2}, \mathrm{~F}_{4}, \mathrm{~F}_{6}$ & $\mathrm{~F}_{1}, \mathrm{~F}_{2}, \mathrm{~F}_{3}, \mathrm{~F}_{6}$ & $\mathrm{~F}_{2}$ & \\
\hline $\mathbf{F}_{3}$ & $\mathrm{~F}_{1}, \mathrm{~F}_{2}, \mathrm{~F}_{3}, \mathrm{~F}_{4}, \mathrm{~F}_{6}$ & $\mathrm{~F}_{1}, \mathrm{~F}_{3}, \mathrm{~F}_{6}$ & $\mathrm{~F}_{1}, \mathrm{~F}_{3}, \mathrm{~F}_{6}$ & \\
\hline $\mathbf{F}_{4}$ & $\mathrm{~F}_{4}$ & $\mathrm{~F}_{1}, \mathrm{~F}_{2}, \mathrm{~F}_{3}, \mathrm{~F}_{4}, \mathrm{~F}_{5}, \mathrm{~F}_{6}$ & $\mathrm{~F}_{4}$ & I \\
\hline $\mathbf{F}_{5}$ & $\mathrm{~F}_{1}, \mathrm{~F}_{4}, \mathrm{~F}_{5}, \mathrm{~F}_{6}$ & $\mathrm{~F}_{5}$ & $\mathrm{~F}_{5}$ & \\
\hline $\mathbf{F}_{6}$ & $\mathrm{~F}_{1}, \mathrm{~F}_{2}, \mathrm{~F}_{3}, \mathrm{~F}_{4}, \mathrm{~F}_{6}$ & $\mathrm{~F}_{1}, \mathrm{~F}_{2}, \mathrm{~F}_{3}, \mathrm{~F}_{5}, \mathrm{~F}_{6}$ & $\mathrm{~F}_{1}, \mathrm{~F}_{2}, \mathrm{~F}_{3}, \mathrm{~F}_{6}$ & \\
\hline
\end{tabular}

Table 7.Iteration 2

\begin{tabular}{clllc}
\hline $\begin{array}{c}\text { QEFs } \\
\left(\mathbf{F}_{\mathbf{i}}\right)\end{array}$ & Reachability set & Antecedent set & Intersection set & Level \\
$\mathbf{A}\left(\mathbf{F}_{\mathbf{i}}\right)$ & $\mathrm{F}_{1}, \mathrm{~F}_{2}, \mathrm{~F}_{3}, \mathrm{~F}_{6}$ & $\mathrm{~F}_{1}, \mathrm{~F}_{2}, \mathrm{~F}_{3}, \mathrm{~F}_{5}, \mathrm{~F}_{6}$ & $\mathrm{~F}_{1}, \mathrm{~F}_{2}, \mathrm{~F}_{3}, \mathrm{~F}_{6}$ & II \\
$\mathbf{F}_{\mathbf{1}}$ & $\left.\mathrm{F}_{1}, \mathrm{~F}_{2}, \mathrm{~F}_{6}\right)$ & $\mathrm{F}_{2}$ & \\
$\mathbf{F}_{\mathbf{2}}$ & $\mathrm{F}_{1}, \mathrm{~F}_{2}, \mathrm{~F}_{3}, \mathrm{~F}_{6}$ & $\mathrm{~F}_{2}, \mathrm{~F}_{3}, \mathrm{~F}_{6}$ & $\mathrm{~F}_{1}, \mathrm{~F}_{3}, \mathrm{~F}_{6}, \mathrm{~F}_{6}$ & \\
$\mathbf{F}_{\mathbf{3}}$ & $\mathrm{F}_{1}, \mathrm{~F}_{5}, \mathrm{~F}_{6}$ & $\mathrm{~F}_{5}$ & $\mathrm{~F}_{5}$ & \\
$\mathbf{F}_{\mathbf{5}}$ & $\mathrm{F}_{1}, \mathrm{~F}_{2}, \mathrm{~F}_{3}, \mathrm{~F}_{6}$ & $\mathrm{~F}_{1}, \mathrm{~F}_{2}, \mathrm{~F}_{3}, \mathrm{~F}_{5}, \mathrm{~F}_{6}$ & $\mathrm{~F}_{1}, \mathrm{~F}_{2}, \mathrm{~F}_{3}, \mathrm{~F}_{6}$ & II \\
$\mathbf{F}_{\mathbf{6}}$ & & & & \\
\hline
\end{tabular}


Table 8.Iteration 3

\begin{tabular}{cllll}
\hline $\begin{array}{c}\text { QEFs } \\
\left(\mathbf{F}_{\mathbf{i}}\right)\end{array}$ & Reachability set & Antecedent set & Intersection set & Level \\
$\mathbf{R}\left(\mathbf{F}_{\mathbf{i}}\right)$ & $\mathbf{A}\left(\mathbf{F}_{\mathbf{i}}\right)$ & $\mathbf{R}\left(\mathbf{F}_{\mathbf{i}}\right) \cap \mathbf{A}\left(\mathbf{F}_{\mathbf{i}}\right)$ & \\
\hline $\mathbf{F}_{\mathbf{2}}$ & $\mathrm{F}_{2}$ & $\mathrm{~F}_{2}, \mathrm{~F}_{3}$ & $\mathrm{~F}_{2}$ & III \\
$\mathbf{F}_{\mathbf{3}}$ & $\mathrm{F}_{2}, \mathrm{~F}_{3}$ & $\mathrm{~F}_{3}$ & $\mathrm{~F}_{3}$ & \\
$\mathbf{F}_{\mathbf{5}}$ & $\mathrm{F}_{5}$ & $\mathrm{~F}_{5}$ & $\mathrm{~F}_{5}$ & III \\
\hline
\end{tabular}

Table 9.Iteration 4

\begin{tabular}{cllll}
\hline $\begin{array}{c}\text { QEFs } \\
\left(\mathbf{F}_{\mathbf{i}}\right)\end{array}$ & $\begin{array}{l}\text { Reachability set } \\
\mathbf{R}\left(\mathbf{F}_{\mathbf{i}}\right)\end{array}$ & $\begin{array}{l}\text { Antecedent set } \\
\mathbf{A}\left(\mathbf{F}_{\mathbf{i}}\right)\end{array}$ & $\begin{array}{l}\text { Intersection set } \\
\mathbf{R}\left(\mathbf{F}_{\mathbf{i}}\right) \cap \mathbf{A}\left(\mathbf{F}_{\mathbf{i}}\right)\end{array}$ & Level \\
\hline $\mathbf{F}_{3}$ & $\mathrm{~F}_{3}$ & $\mathrm{~F}_{3}$ & $\mathrm{~F}_{3}$ & $\mathbf{I V}$ \\
\hline
\end{tabular}

\subsection{Conical matrix}

In this step of ISM approach, a conical matrix (Table 10) is developed by clubbing the QEFs of same level across the rows and columns of FRM.

Table 10.Conical Matrix

\begin{tabular}{ccccccccc}
\hline QEFs & $\mathbf{F}_{\mathbf{4}}$ & $\mathbf{F}_{\mathbf{1}}$ & $\mathbf{F}_{\mathbf{6}}$ & $\mathbf{F}_{\mathbf{2}}$ & $\mathbf{F}_{\mathbf{5}}$ & $\mathbf{F}_{\mathbf{3}}$ & Driving Power & Rank \\
\hline $\mathbf{F}_{\mathbf{4}}$ & 1 & 0 & 0 & 0 & 0 & 0 & 1 & III \\
$\mathbf{F}_{\mathbf{1}}$ & 1 & 1 & 1 & 1 & 0 & 1 & 5 & I \\
$\mathbf{F}_{\mathbf{6}}$ & 1 & 1 & 1 & 1 & 0 & 1 & 5 & I \\
$\mathbf{F}_{\mathbf{2}}$ & 1 & 1 & 1 & 1 & 0 & 0 & 4 & II \\
$\mathbf{F}_{\mathbf{5}}$ & 1 & 1 & 1 & 0 & 1 & 0 & 4 & II \\
$\mathbf{F}_{\mathbf{3}}$ & 1 & 1 & 1 & 1 & 0 & 1 & 5 & I \\
$\begin{array}{c}\text { Dependence } \\
\text { power }\end{array}$ & 6 & 5 & 5 & 4 & 1 & 3 & & \\
Rank & I & II & II & III & $\mathbf{V}$ & IV & & \\
\hline
\end{tabular}

Table 10 shows the driving power and dependence power of each QEF. The driving power of a specific QEF is computed by totalling the number of QEFs (including itself), which it may help to attain whereas the dependence power is computed by totalling the number of QEFs, which may help in attaining it. Moreover, Table 10 also shows the ranking of each QEF on the basis of driving power and dependence power.

\subsection{Digraph development}

Digraph or directed graph (including transitivity links) is developed from the conical matrix (Table 10). Final digraph (Figure 2) is obtained after removing the indirect links. 
International Journal of Recent advances in Mechanical Engineering (IJMECH) Vol.4, No.2, May 2015

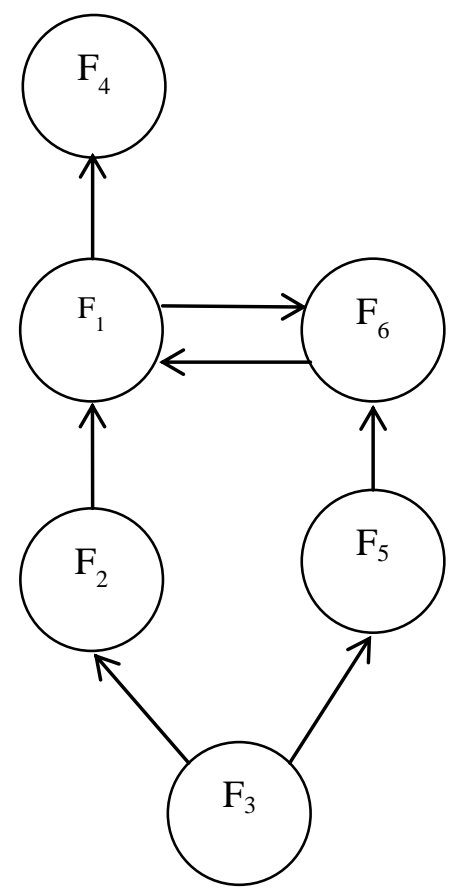

Figure 2.Digraph showing levels of QEFs

\subsection{ISM model development}

In this step of ISM approach, digraph (Figure 3) is developed into an ISM model by substituting nodes of the elements with statements.

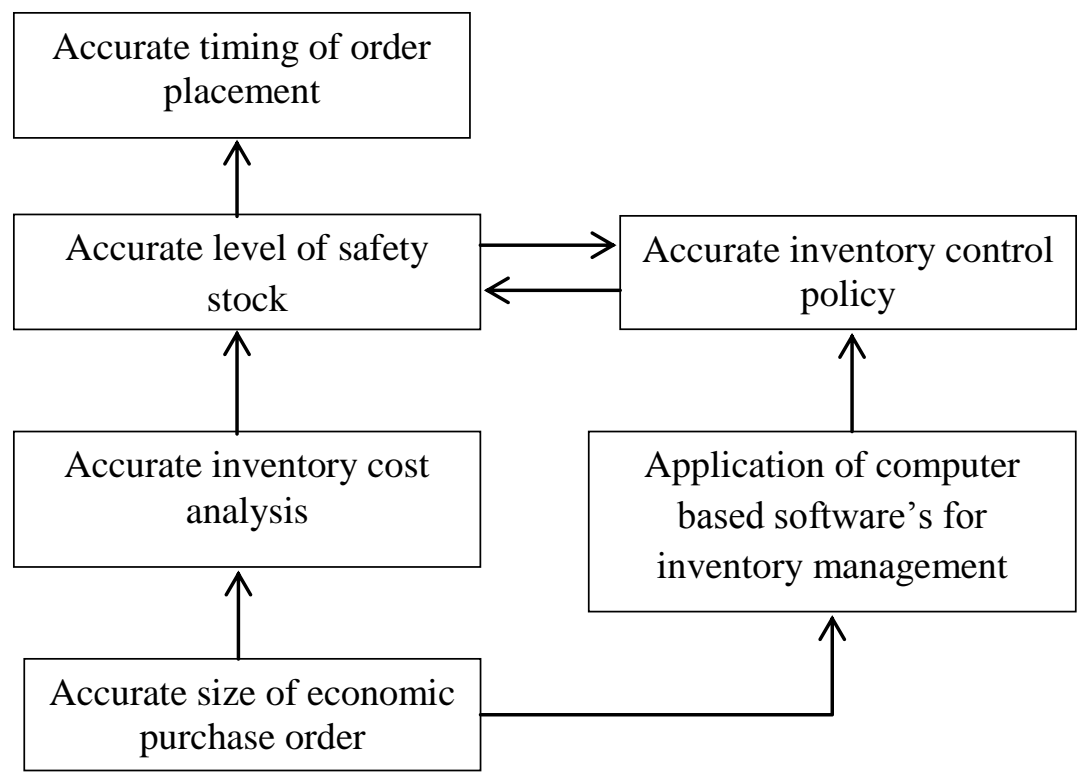

Figure 3.Interpretive structural model showing levels of QEFs 


\section{MICMAC ANALYSIS}

MICMAC analysis is performed for obtaining the new understandings into the dependencies existing among the QEFs identified by ISM approach. The main purpose of the MIMAC analysis is to analyse the drive power and dependence power of QEFs. MICMAC analysis is carried out in order to classify the QEFs into different categories as follows:

- Autonomous QEFs: The QEFs in this category have weak drive power and weak dependencepower. This category lies in first quadrant of the driver powerdependencepower diagram.

- Dependent QEFs: The QEFs in this category have weak drive power and strong dependencepower. This category lies in second quadrant of the driver powerdependencepower diagram.

- Linkage QEFs: The QEFs in this category have strong drive power and strong dependencepower. This category lies in third quadrant of the driver power-dependence power diagram.

- Independent QEFs: The QEFs in this category have strong drive power and weak dependencepower. This category lies in fourth quadrant of the driver power-dependence power diagram.

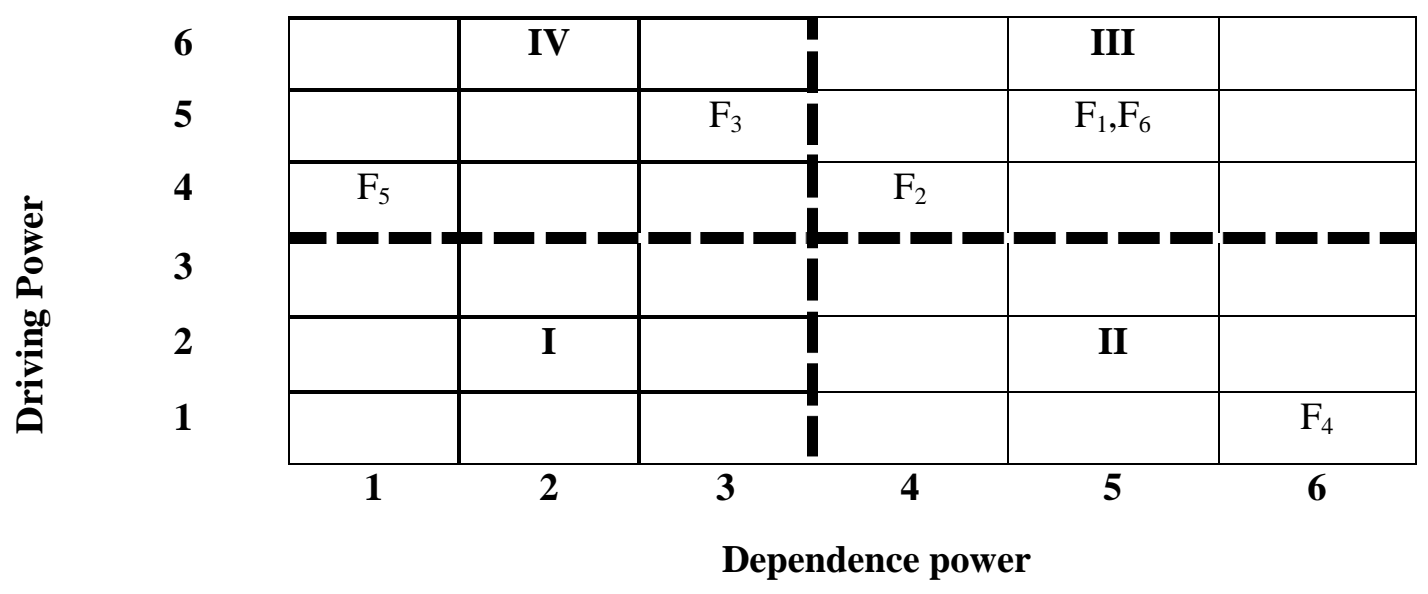

Figure 4.Driver power-dependence power diagram

\section{DisCUSSION AND CONCLUSION}

The main objective of the present work is to analyze the contextual relationship among the various quality enabled factors (QEFs) of inventory control system stage of production system life cycle (PSLC). These QEFs affects the decisions in inventory control system stage. For this purpose, an ISM-based model on QEFs for inventory control system has been developed. These QEFs assumes importance because consideration of these factors affects the decisions in inventory control system stage. Some of the major QEFs have been deliberated here and employed into an ISM model to analyze the interaction among these QEFs. The present work 
accentuate that there is need to consider these QEFs in having the better decisions in the inventory control system stage.

The driver power-dependence power matrix diagram (Figure 4) gives some valuable insights about the relative importance and the interdependencies among the inventory control system QEFs.

- Figure 4 shows that there are no autonomous QEFs in the driver power-dependence power diagram. The absence of these QEFs in the present study shows that all the reflected QEFs play a significant role in affecting the inventory control system decisions.

- QEFs such as "Accurate timing of order placement" own weak driving power but strong dependence power. They are seen at the top-level of the ISM hierarchy.

- QEFs such as "Accurate level of safety stock" and "Accurate inventory control policy" are the linkage QEFs. These QEFs have strong driving power as well as strong dependence power.

- Finally, the driver power-dependence diagram specifies that independent QEFs are "Accurate inventory cost analysis", "Application of computer based software's for inventory management" and "Accurate size of economic purchase order". These QEFs lies at the bottom of ISM hierarchy possessing strong driving power and weak dependence power. Thus, management should give high priority in utilizing these QEFs which have ability of influencing the other QEFs. They may be treated as the "major QEFs" in the inventory control system stage.

The manufacturing managers or decision makers can get a vision about the driving power and dependence power of the QEFs and can cultivate appropriate approaches to handle them. The major limitations of the present work are as follows:

(a) The survey is limited to the Indian manufacturing organizations.

(b) The ISM model has been developed on the basis of inputs of experts. This may lead to some biasness.

(c) ISM model is not statistically validated.

(d) The developed ISM model fails to quantify the impact of each QEF on the inventory control system stage decisions.

So, in future following research work may be carried out:

(a) More number of QEFs can be identified.

(b) The developed ISM model can be validated by using "Structural Equation Modelling" (SEM) approach. SEM approach has the ability to test such developed model.

(c) Graph theoretic approach (GTA) can be applied to quantify the QEFs to know their impact in the inventory control system stage. 


\section{REFERENCES}

[1] Jose, T.V., Jayakumar, A. and Sijo, M.T. (2013) Analysis of inventory control techniques: A comparative study, International Journal of Scientific and Research Publications, 3(3), 1-6.

[2] Mathaba, S., Dlodlo, N., Smith, A. and Adigun, M. (2011) The use of RFID and Web 2.0 Technologies to Improve Inventory Management in South African Enterprises, Electronic Journal Information Systems Evaluation, 14(2), 228-241.

[3] Liang, Y. (1997) The development of an intelligent inventory management system, Doctor of Philosophy thesis, Department of Computer and Mathematical Sciences, University of Salford, Salford, U.K.

[4] Ellen, M. and Wagner, B. (2009) Concepts in Enterprise Resource Planning, Cengage Learning.

[5] Warfield, J.N. (1974) Structuring Complex Systems, Battelle Monograph, Battelle Memorial Inst. 4, Columbus, $\mathrm{OH}$.

[6] Jolhe, D.A. and SubashBabu, A. (2014) 'Modifications in interpretive structural modelling methodology to enhance its applicability in group decision process and power of discrimination', International Journal of Business Excellence, Vol. 7, No. 3, pp. 281-348.

[7] Malone, D. (1975) An introduction to the application of interpretive structural modelling, Proceedings of the Institute of Electrical and Electronics Engineers, Vol. 63, pp. 397-404.

[8] Sage, A.P. (1977) Interpretive Structural Modeling: Methodology for Large-Scale Systems, McGraw-Hill, NewYork.

[9] Govindan, K., Palaniappan, M., Zhu, Q. and Kannan, D. (2012) Analysis of third party reverse logistics provider using interpretive structural modeling, International Journal of Production Economics, Vol. 140, pp. 204-211.

[10] Kannan, G., Devika, K. and NoorulHaq, A. (2010) Analyzing supplier development criteria for an automobile industry, Industrial Management \& Data Systems, Vol. 110, No. 1, pp. 43-62.

[11] Qureshi, M.N., Kumar, D. and Kumar, P. (2007) 'Modelling the logistics outsourcing relationship variables to enhance shippers' productivity and competitiveness in logistical supply chain', International Journal of Productivity and Performance Management, Vol. 56, No. 8, pp.689-714.

[12] Attri, R., Dev, N. and Sharma, V. (2013), "Interpretive structural modelling (ISM) approach: an overview", Research Journal of Management Sciences, Vol. 2 No. 2, pp. 3-8.

[13] Attri, R., Grover, S., Dev, N. and Kumar, D. (2013), "Analysis of barriers of total productive maintenance (TPM)", International Journal of System Assurance Engineering and Management, Vol. 4 No. 4, pp. 365-377.

[14] Attri, R., Grover, S., Dev, N. and Kumar, D. (2013), "An ISM approach for modelling the enablers in the implementation of Total Productive Maintenance (TPM)", International Journal of System Assurance Engineering and Management, Vol. 4 No. 4, pp. 313-326.

[15] Raj, T. and Attri, R. (2011) Identification and modelling of barriers in the implementation of TQM, International Journal of Productivity and Quality Management, Vol. 28 No. 2, pp. 153-179.

[16] Raj, T., Attri, R. and Jain, V. (2012) Modelling the factor affecting flexibility in FMS, International Journal of Industrial and System Engineering, Vol. 11 No. 4, pp. 350-374.

[17] Attri, R. and Grover, S. (2015b) 'Analyzing the scheduling system stage of production system life cycle', Management Science Letters, Vol. 5, No. 5, pp. 431-442.

[18] Pandi, A.P., Sethupathi, P.V.R. and Jeyathilagar, D. (2014) The IEQMS model for augmenting quality in engineering institutions - an interpretive structural modelling approach, Total Quality Management \& Business Excellence, Available online at http://www.tandfonline.com/doi/full/10.1080/14783363.2014.978647.

[19] Faisal, M.N. (2010) Analysing the barriers to corporate social responsibility in supply chains: an interpretive structural modelling approach, International Journal of Logistics Research and Applications, Vol. 13, No. 3, pp. 179-195.

[20] Singh, M.D. and Kant, R. (2008) Knowledge management barriers: An interpretive structural modeling approach, International Journal of Management Science and Engineering Management, Vol. 3, No. 2, pp. 141-150.

[21] Mehta, N., Verma, P. and Seth, N. (2014) Total quality management implementation in engineering education in India: an interpretive structural modelling approach, Total Quality Management \& Business, Vol. 25, No. 1-2, pp. 124-140. 
International Journal of Recent advances in Mechanical Engineering (IJMECH) Vol.4, No.2, May 2015

[22] Govindan, K., Kannan, D., Mathiyazhagan, K., de Sousa Jabbour, A.B.L. and Jabbour, C.J.C. (2013) Analysing green supply chain management practices in Brazil's electrical/electronics industry using interpretive structural modelling, International Journal of Environmental Studies, Vol. 70, No. 4, pp. 477-4793. 